\title{
Orcas are social mammals
}

\begin{abstract}
After humans, orcas (Orcinus orcas) are the most widely distributed mammals on Earth. ${ }^{1}$ They are incredibly effective predators, commonly referred to as 'wolves of the sea.' Although they are frequently dubbed killer whales, they are actually the largest member of the oceanic dolphin family (Delphinidae). ${ }^{3}$ Given that they are well-adapted to any climate, they can be found in numerous aquatic locations ${ }^{4}$ including the Antarctic and Arctic regions as well as in tropical areas. ${ }^{5}$ They are unrivaled oceanic apex predators, possessing a number of qualities that suggest considerable intelligence. ${ }^{6}$ Following the sperm whale, orcas have the second largest brain of all oceanic mammals. ${ }^{7}$ Moreover, their highly evolved communication manners, usage of echolocation and compelling sleep patterns all attest to the impressiveness of this group of marine mammals. However, they need to be recognized and accepted as outstanding social creatures that can coexist with humans.
\end{abstract}

Keywords: killer whale, dolphin, behavior, social habits, language
Special Issue - 2018

\author{
Marina Kachar,' Ewa Sawosz, ${ }^{2}$ André \\ Chwalibog ${ }^{3}$ \\ 'Department of Environmental Protection, Educons University, \\ Serbia \\ ${ }^{2}$ Department of Animal Nutrition and Biotechnology, Warsaw \\ University of Life Sciences, Poland \\ ${ }^{3}$ Department of Veterinary and Animal Sciences, University of \\ Copenhagen, Denmark
}

\author{
Correspondence: André Chwalibog, Department of \\ Veterinary and Animal Sciences, University of Copenhagen, \\ Groennegaardsve j 3, I 870 Frederiksberg, Denmark, Tel +4540 \\ 9635 73; Email ach@sund.ku.dk
}

Received: June 21, 2018| Published: July 16, 2018

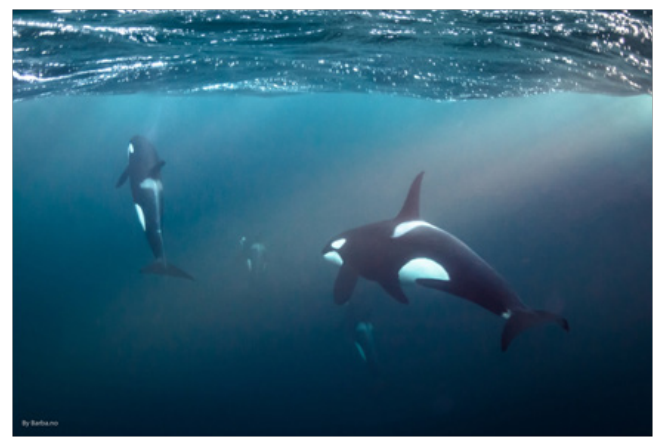

Image from Andreas B. Heide (Barba.no)

\section{Introduction}

Orcas are marine carnivores that are easily recognizable by the distinctive black and white coloring of their rounded bodies, along with the dorsal fin in the middle of their backs. They can grow to up to 7.7meters (females) and 9.0meters (males), and weigh up to six tons. ${ }^{6}$ In the wild, this warm-blooded mammal lives from 50 to 90 years. ${ }^{8}$ Depending on the pod to which they belong, orcas' dorsal fin may be tapered and pointed in a triangular fashion, long, or curved and rounded towards the end. The dorsal fin is quite flexible in newborn orcas, but it stiffens with age. When a male orca begins to mature, its dorsal fin starts growing rapidly up to that point of resembling a female's dorsal fin, and it then starts to straighten out, regularly losing its curve and becoming more distinctive compared to the female fin. In the wild, an orca's dorsal fin is upright, but in captivity it often collapses to one side due to several possible reasons such as stress, lack of exercise and dehydration. The dorsal fin is very important because it helps the orca to regulate its body temperature. As orcas swim, the excess heat is accumulated and released into the water and air via the dorsal fin. ${ }^{9}$

Orcas are born with a single blowhole (unlike the baleen whale, which has two blowholes). ${ }^{6}$ They cannot breathe when submerged and instead must breathe air above the water's surface using the blowhole at the top of their heads, which effectively works like a giant nostril. ${ }^{8}$
The orca must quickly expel used air from its lungs at the surface, which produces the loud distinguishing sound or "blow. ${ }^{10}$ In most cases, orcas breathe in 20second intervals in succession (3-4times), and then submerge for a longer period of time. ${ }^{8}$ Orcas are able to control the flow of blood to their brains and hearts, which ensures that they do not suffer from a lack of oxygen while they are submerged. ${ }^{10}$ When swimming, orcas can reach incredible speeds (for their size) of approximately $40 \mathrm{~km} / \mathrm{hr}$, rendering them one of the fastest marine mammals. Yet when cruising with their pod members, their speed is only about $5-10 \mathrm{~km} / \mathrm{hr}^{8}$

Orcas are known for mating all year long, unlike other cetacean species. Males reach breeding maturity when they are about 5.6meters long, and females reach breeding maturity when they are about 4.9 meters long. ${ }^{11}$ Female orcas have relationships with multiple partners, while males do not breed within the same pod, which keeps the genetic pool very vibrant. ${ }^{8}$ Thus, after maturation male orcas venture away from their family pod in search of females from other orca families, but they will always return. The mothers give birth approximately every three to $10 y e a r s$, and their pregnancy lasts 17 months, which is longer than any other marine mammal. ${ }^{8}$ Calves are born about 2.1 meters long. ${ }^{12}$ Orca calves are one of the few animals usually born tail first. ${ }^{13}$ In her lifetime, a female orca may have four to six offspring. ${ }^{14}$ Orca calves nurse for about one year, about five to ten seconds at a time, during the day and night. A calf will remain with its mother for at least two years, but it has been noted that many orcas live with their mothers for their entire lives..$^{15}$ It has been proven that separation between mothers and calves is extremely stressful for these cetaceans. ${ }^{16}$

An impressive combination of high intelligence, outstanding hunting techniques, and tremendous physical power makes the orca one of the planet's leading predators. This complex creature has an array of tremendous social skills. ${ }^{6}$ Orcas have demonstrated captivating social habits, such as living in highly distinctive lifelong pods, as well as exceptional memory and communication skills (amongst other qualities), which have enabled them to acquire immense popularity amongst cetacean admirers. ${ }^{16}$ Their various interesting social habits, along with their communication patterns, render them surprisingly 
relatable to humans. ${ }^{17}$ Their brain is nearly four times the size of a human brain, weighing almost seven kilograms. ${ }^{7}$ In analyzing their brains, researchers have developed various hypotheses regarding orcas' intelligence. ${ }^{16}$ Based on observations both in captivity and in the wild, orcas seem to exhibit a wide range of emotions, including frustration, anger, fear, joy and even self-awareness, which makes them enthralling to observe as social mammals. ${ }^{18}$

\section{Misconceptions concerning the name}

Orcinus orca is one of the oceanic dolphin family's 35 species, and probably evolved around 11 million years ago. ${ }^{19}$ Despite having morphological similarities with false killer whales (Pseudorca crassidens), pilot whales (Globicephala melas) and pygmy killer whales (Feresa attenuate), its closest relatives are the snub fin dolphin (Orcaella heinsohni) and Irrawaddy dolphin (Oracaella brevirostris) ${ }^{20}$ The reason that people refer to orcas as whales is because sailors historically called these marine mammals 'whale killers' after witnessing them preying on whales and other marine mammals. ${ }^{21,22}$ In spite of their ferocious nickname 'killer,' they have never been known to show aggression to humans in the wild.

\section{Life in the pod}

These extraordinary mammals tend to swim in sea depths of between 20-60meters, and constantly move in remarkably wellbalanced and permanent pods, led by older females..$^{23}$ Researchers have identified three types of pods: resident (primarily residing in one area); transient (traveling over a relatively wide area); and offshore pods (roaming the deep blue waters). Large differences can be seen in the behaviors, hunting patterns, and communication and dietary habits between distinct pods. ${ }^{24}$ Resident pods are less aggressive, and they primarily eat fish, whereas transient pods are far more aggressive and tend to eat bigger marine species. ${ }^{25}$ Orcas travel and hunt like wolves and lions in matriarchal social structures that may contain 50 or more individuals. ${ }^{26}$ Some pods combine to form so-called groups of more than 100 orcas. $^{6}$ The individuals within the pods swim in relatively close proximity to one another, around 100 meters apart. ${ }^{27}$ The orcas within the pods usually comprise a group of diverse generations of related individuals, made up of approximately $20 \%$ calves, $20 \%$ males and $60 \%$ females. $^{9}$ The social group (pod) has established hierarchies ${ }^{24}$ with a social structure that has been considered one of the most stable of any animal species. ${ }^{28}$ The development of new pods can take generations due to the animals' long lifespan. ${ }^{29}$

Even though they can regularly be spotted near to coastlines, orcas are known to dive to depths of about 300 meters in search of food. ${ }^{29}$ Depending on their diet and age, they can consume up to $10 \%$ of their body weight every day. ${ }^{10,30}$ Orcas are known for eating any animal they may encounter, and as such exist at the top of the food chain as apex predators: their meals may consist of whales, seals, sharks, squid, fish, other dolphins, and in some cases, birds. ${ }^{15}$ The pod can swim up to 160kilometers in one day in search of food. ${ }^{31}$ Having worked together to catch prey, orcas will share their meal with the members of the pod, especially with the youngest pod members. Their hunting techniques may vary depending on the pod, but the unity of the pod is constant even during hunts. ${ }^{9}$ Their close-knit bonds, in addition to their exceptional hunting methods, make these marine mammals one of the most feared in the animal kingdom. ${ }^{32}$ It has been documented that pod members will force large numbers of fish into one area of the ocean, and will then take turns feeding. However, even more compelling is the fact that they may beach themselves (slide onto the shore) to scare penguins or seals into the water for other pod members to hunt. ${ }^{33}$ In polar regions, orcas are known to knock down the blocks of ice on which seals rest in order to hunt them. In order to perform such an act, they use their bodies to create forceful waves, causing the seals to slide into the water. When hunting humpback whales in Australian waters, orcas are known to cooperate, separating mothers from calves in order to expedite the hunt. ${ }^{34}$ It has been documented that orcas use their prevailing tails, called 'flukes,' as weapons during their hunts. Furthermore, pod members may even leave their pods for a few hours in search of prey, returning afterwards ${ }^{35}$ This is interesting because in studying orcas' behavior, scientists have realized that there seems to be very little or almost no migration due to water temperatures or weather; they only tend to venture into different water areas if food becomes scarce. Given that most cetaceans demonstrate standard migration patterns, this behavior renders orcas rather distinctive. ${ }^{36}$

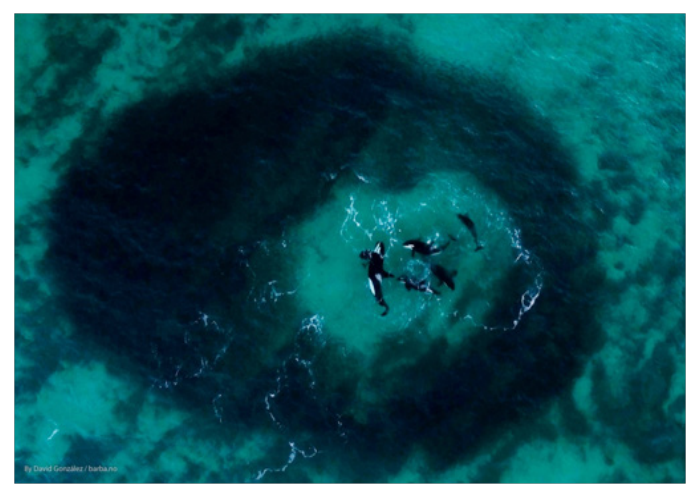

Image from Andreas B. Heide (David Gonzalez/barba.no)

Orcas are very similar to humans in their care for their offspring. Calves are not only known to receive education from their mothers, but also discipline and 'punishment,' which helps make them relatable to humans. Signs of a female orca's 'anger' include strong head movements, hitting their tail in the water, emitting unusual noises using their teeth, and a range of other rather intimidating body movements. ${ }^{37}$ Mothers form exceptionally close bonds with their sons. ${ }^{38}$ If a mother orca is alive but has no surviving sons, she will swim not just with her daughters but with her grandchildren as well. ${ }^{39}$ The adult daughters (who might have their own offspring), may separate from their mother to a certain extent, but will not travel far from her. ${ }^{8}$ Orcas are very protective of their young: it has been documented that adolescent females often assist their mother in caring for the young. Such 'babysitting' by young females prepares them for the later responsibility of becoming a mother. Males within the pod are also known to babysit. ${ }^{40}$ The orca is one of just four species on the planet in which females routinely experience menopause; indeed, most animals retain the ability to reproduce until death. The other three species that experience menopause and stop breeding years before the end of their lives are humans, short-finned pilot whales, and false killer whales. ${ }^{41}$

\section{Social habits}

In studying orcas' lifestyles, many marine biologists have come to the conclusion that these animals possess their own culture, akin to humans. ${ }^{42,43}$ This conclusion is based on the fact that diverse pods have diverse personalities, behaviors, ways of communication and diets; moreover, social contact and bonding with other pod members are highly valued. It has been noted that orcas enjoy playing for a long 
time. An activity they seem to adore is called breaching, which is an entertaining performance whereby the orca jumps out of the water and splashes the surface with its entire body. The reason for this activity is not clear, but it is quite incredible to watch. Breaching probably constitutes a means of communicating, as well as providing a way of shaking off parasites and gaining a better view of their surroundings (for potential prey), as well as simply for fun. ${ }^{8}$ Tail flapping (the act of slapping the water surface with the fluke) is another interesting habit because it is never exhibited in exactly the same way: sometimes the movement is careful and gentle, but it can also represent a sudden and loud crack through the air and water. ${ }^{16}$ Spy-hopping is another orca behavior that receives considerable attention from tourists. ${ }^{6}$ It consists of an orca holding itself vertically in the water and kicking with its tail (fluke) in order to hold its head above the water surface. Some orcas can practice this behavior for several minutes, and it is most frequently seen around Vancouver Island in British Columbia, Canada. ${ }^{9}$ Orcas have also been spotted rubbing themselves on rocks in order to remove dead skin cells, ${ }^{16}$ as smooth skin increases their swimming efficiency.

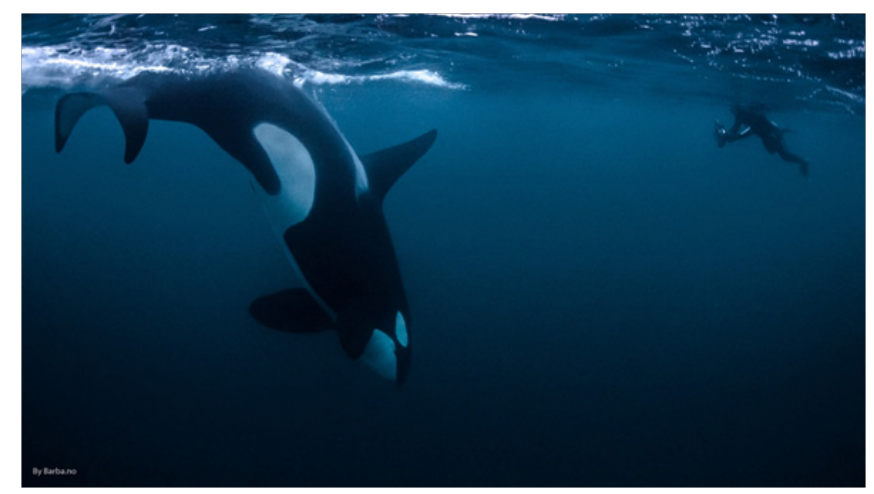

Image from Andreas B. Heide (Barba.no)

\section{Brain}

The orca's skull is oval-shaped and contains one of the biggest brains on Earth. ${ }^{7}$ An orca's brain is one of its most remarkable instruments used in everyday life, yet it is not completely explored. Many studies have indicated that orcas possess a remarkable photographic memory. In tests conducted on orcas in captivity, the animals were able to recall testing patterns up to 25years after first being conducted. ${ }^{41}$ However, what makes their brains so captivating is the fact that areas of the brain that are known to encompass emotional thought and response are larger (percentage wise) in orcas than in any other animal. ${ }^{10}$ Neurologists explain that the area called the limbic system is responsible for processing all emotions. The orca's brain contains an extra lobe of tissue immediately next to the limbic system and neocortex called the paralimbic lobe, which humans do not possess. The paralimbic lobe is an outgrowth of the areas of the brain that are known to control communication and social emotions in all other mammals, rendering it possible that orcas experience feelings, emotions and social connections such as love, joy and grief on a level that human beings cannot even comprehend. It is certain that orcas can understand hand signals, symbols on flashcards, and vocal cues when interacting with humans.$^{44}$ Furthermore, it has been proven that orcas can understand numbers and can recognize themselves in a mirror. ${ }^{41}$

\section{Sleep patterns}

Orcas can be found in the oceanic surface layers while sleeping. They sleep from five to eight hours a day. However, there is a big difference in the ways in which orcas sleep in comparison to humans. Given that their sleep is unihemispheric (also described as 'onesided sleep,' which in reality means they are only half-asleep), their breathing patterns differ from humans, who breathe unconsciously during sleep. ${ }^{45}$ Orcas are conscious breathers, which accounts for why they can never fall completely asleep. The orca shuts down one hemisphere of its brain as well as the opposite eye controlled by that hemisphere, while the other hemisphere and eye remain alert. This makes them awake and asleep simultaneously. EEG studies with dolphins have helped researchers to determine this kind of sleep. ${ }^{46}$ If the orca were to go into an unconscious state of deep sleep, it would suffocate and drown. An interesting fact is that orca calves spend the first months of their lives wide awake, with no sleep whatsoever. ${ }^{40}$ Indeed, adult orcas can be seen sleeping while the young calves continue swimming nearby. ${ }^{47}$ There are many reasons behind this type of 'non-sleeping' among orca calves. One is that this could be a way of staying safe from potentially harmful predators while they are still young; after all, mortality rates are high amongst newborn orcas. The second key reason is that these infants need to keep their bodies warm through constant activity until they grow older and develop blubber. ${ }^{40}$ Even during sleep, members of a pod will form a very tight circle, synchronizing their movements and breathing. Resting in such a way also helps the pod members to avoid boats at a time when only half of their brain is awake. ${ }^{46}$

\section{Echolocation and language}

Orcas have very well-developed senses. They can hear an ample range of sounds, possess admirable vision in and out of the water, and their skin is very sensitive to the touch. ${ }^{48}$ Like most dolphins, orcas use a biological sonar called echolocation to communicate, but also to capture prey when vision cannot be used. ${ }^{6}$ During their underwater search for food (or during the night), echolocation facilitates the location of objects and prey. ${ }^{41}$ Orcas will make a sound that travels through the water. When the sound wave hits an object, it bounces back and returns to the orca. Using echolocation, orcas can detect other animals or objects in the area, as well as their size and shape. The clicks emitted through a fatty organ in the forehead (called the melon) hit objects and bounce back to the orca with important information. ${ }^{6}$ Moreover, due to the fact that marine mammals are able to detect echolocation, orcas can decrease the clicks they emit when hunting, so as to not advertise their presence. ${ }^{38}$

The so-called orca language is one of the most complex within any animal species. ${ }^{8}$ The calls that orcas produce are as loud as jet plane engines, making communication possible at all times, regardless of distance between the animals. ${ }^{49}$ Every pod 'sounds' very different, hence the noises they produce are characteristic only to their pod. ${ }^{48}$ They communicate with each other through very distinctive whistles and definite calls, in addition to low frequency pops..$^{50}$ The single blowhole at the top of the head is used not only to breathe, but also to communicate, constantly chattering amongst themselves. ${ }^{17,51}$ Phonic lips are delicate folds of skin within the blowhole, which make the orca able to create different communicative clicks. Whistle sounds are produced by the larynx (enabling them to create more than one sound at a time), since they do not have vocal cords. ${ }^{49}$ Orcas use their jaws to 
make clapping sounds, which can be heard throughout the water. ${ }^{49}$ In possessing their own dialect of sounds, each pod member can recognize their pod from about 12 kilometers away based on specific calls. ${ }^{31}$ Whistles are used for private and close-range communication, while pulsed calls are used for long-range communication. Learning their mother's dialect is a slow process for the baby orca. The young orca needs about two years of practice to attain a full repertoire of sounds. Mothers have been recorded using exceptionally diverse sounds when communicating with their offspring ('baby talk'), in contrast to the sounds they use to communicate with adult members of the pod. ${ }^{8}$ Even though they have their own pod language, when they talk to other pods they use a more communal language. ${ }^{9}$ Just like people, orcas that live great distances apart possess completely different dialects. An example is the results obtained from an analysis of Norwegian and Icelandic orca pods: 23 different calls made by Norwegian and 24 different calls made by Icelandic orcas were distinguished, yet the two populations did not share any of the same calls. ${ }^{52}$ It has been observed that orcas have specific ways of communicating with people as well. In the wild, it has been recognized that orcas are far more cooperative with humans, as proven in the case of the orcas of Eden, Australia. This finding was documented in the 1840 s by whaling overseer Sir Oswald Brierly in his extensive diaries. ${ }^{53}$ A group of orcas off the coast of Eden assisted in whale hunting. The orcas would find target whales, lead them into a bay, and then alert the whalers of their presence in order to help catch them. The leader of the orcas was named Old Tom, and he would be amongst the first to alert the human whalers of the presence of whales by breaching or tail slapping at the mouth of the Kiah River. The whalers would kill the whales and let the orcas feed on the whales before bringing in the whales. Thus, this relationship was clearly exceptionally interdependent.

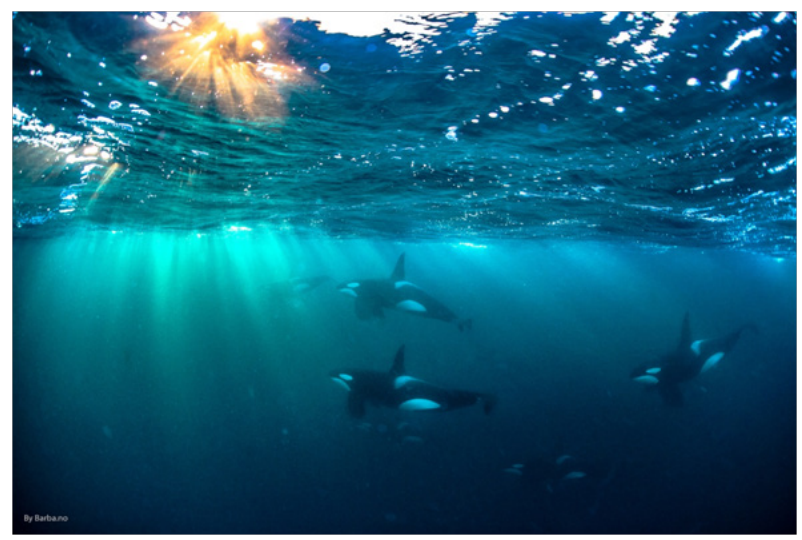

Image from Andreas B. Heide (Barba.no)

\section{Conclusion}

Orcinus orca is certainly one of the finest specimens of marine wildlife. These fully aquatic mammals spend their lives underwater in highly impressive societies, making them one of the most social mammals on Earth. Orcas are incredibly intelligent ocean animals with a great sense of survival. They are also one of the most socially bonded creatures. We can certainly learn a lot from these noteworthy marine mammals, such as the power of unity, strong family ties and emotions. Indeed, orcas need to be understood and acknowledged by humans as outstanding social creatures that coexist with humanity.

\section{Acknowledgements}

We are very grateful to Andreas B. Heide-a marine biologist from Norway and the captain of the sailing yacht Barba, also Mathew Ferraro and David Gonzalez from Way North Films-for providing us with the fascinating images of orcas.

\section{Conflict of interest}

The author declares no conflict of interest.

\section{References}

1. Riesch R, Barrett-Lennard LG, Ellis GM, et al. Cultural traditions and the evolution of reproductive isolation: ecological speciation in killer whales? Biological Journal of the Linnean Society. 2012;106(1):1-17.

2. National Geographic. An orca photographed at SeaWorld in Orlando, Florida.

3. Reynolds III JE, Odell DK, Rommel SA. Marine Mammals of the World. In Biology of Marine Mammals. Washington: Smithsonian Institution Press; 1999

4. The IUCN Red Data Book. Killer Whale Orcinus Orca (Linnaeus, 1758). In Dolphins, Porpoises and Whales of the World. Cambridge: The IUCN Red Book Data, IUCN Gland; 1991. 240 p.

5. Wilson DE, Reeder DM. Mammal Species of the World: A Taxonomic and Geographic Reference. 3rd ed. Johns Hopkins University Press; 2005.

6. Ford JK. Encyclopedia of Marine Mammals. 2nd ed. San Diego: Academic Press; 2008

7. Spear K. How smart are killer whales? Orcas have the 2nd-biggest brain of all marine mammals. 2010.

8. Animal Facts Encyclopedia.

9. Ford KB, Ellis GM, Balcomb KC. Killer Whales: The Natural History and Genealogy of Orcinus Orca in British Columbia and Washington. Vancouver BC: UBC Press; 2000.

10. Whale facts: marine mammal facts and information.

11. MarineBio. Orcas (Killer Whales), Orcinus orca. USA

12. The Columbia Encyclopedia. 6th ed. Killer Whale.

13. SeaWorld Parks \& Entertainment. Habitat \& distribution.

14. J Anderson. Killer Whales. Marine Science. 2003.

15. A Bradford. Orcas: Facts about killer whales. Live Science. 2014.

16. Anderson R, Waayers R, Knight A. Orca behavior and subsequent aggression associated with oceanarium confinement. Animals. 2016;6(8):1-15

17. Tyack PL. Communication and cognition. In Biology of Marine Mammals Washington: Smithsonian Institution Press; 1999.

18. Rose N. Killer Controversy: Why Orcas Should No Longer Be Kept in Captivity. Washington: Humane Society International and The Humane Society of the United States; 2011.

19. Carwardine M. Killer Whales. London: BBC Worldwide; 2001

20. Leduc RG, Perrin W, Dizon A. Phylogenetic relationships among the delphinid cetaceans based on full cytochrome $\mathrm{b}$ sequences. Marine mammal science. 2006;15(3);619-648. 
21. Mathews L. The Natural History of the Whale. New York: Columbia University Press, Weidenfeld and Nicolson; 1978.

22. Ford J. Our changing relationship with the killer whale. In Killer Whales: The Natural History and Genealogy of Orcinus Orca in British Columbia and Washington. Seattle: UBC Press; 1994. 11 p.

23. Robeck TR, Willis K, Scarpuzzi M, et al. Comparisons of life-history parameters between free-ranging and captive killer whale (Orcinus orca) populations for application toward species management. Journal of Mammology. 2015;96(5):1055-1070.

24. Stiffler L. "Smithsonian.com,” August 2011.

25. Kirkevold BC, Lockard JS. Behavioral Biology of Killer Whales. Evolution \& human behavior. 1991;12(1);75-76.

26. Killer Whale. $a-z$ animals.

27. Estes J, Demaster D, Doak D, et al. Whales, Whaling, and Ocean Ecosystems. California: University of California Press; 2007.

28. Ford JK. Killer Whale: Orcinus orca. In Encyclopedia of Marine Mammals. 3rd ed. San Diego: Academic Press; 2002. p. 669-665.

29. Parsons E. An Introduction to Marine Mammal Biology and Conservation. 1st ed. Burlington: Jones \& Bartlett Learning; 2012.

30. Heintzelman DS, A World Guide to Whales, Dolphins, and Porpoises, Tulsa, Oklahoma: Winchester Press, 1981.

31. WDC. Facts about orcas. UK.

32. J Kennedy. Killer whale or orca (orcinus orca). Animals and Nature. 2017.

33. J. Silverman. Why are orca called killer whales? howstuffworks.

34. B Holmes, Orcas seen in unique group ambush-and-kill attack on dolphins. New scientist. 2015.

35. Invasion of the killer whales the killer whale's weapon-its brain. NATURE. 2014

36. J Durban, R Pitman. Antarctic killer whales make rapid, round-trip movements to subtropical waters: evidence for physiological maintenance migrations? Biology Letters. 2011;8 (2):274-277.
37. Killer whale social structure. Killer-whale.org.

38. J Mann, RC Connor, PL Tyack et al. Cetacean Societies Field Studies of Dolphins and Whales. Chicago and London: The University of Chicago Press; 2000

39. Orca social organization. Orca Lab.

40. Lyamin O, Pryaslova J, Lance V, et al. Animal behaviour: Continuous activity in cetaceans after birth. Nature. 2005;435(7046):1177.

41. Killer whale mammal. Encyclopedia Britannica. 2008.

42. J Heimbuch. 5 surprising facts about orcas. Mother Nature network. 2016.

43. C Barras. Orcas are first non-humans whose evolution is driven by culture. New Scientist. 2016.

44. L Crawford. Killer Whales are non-human persons. Grey Matters. 2013.

45. J Green. How Do Killer Whales Sleep? Sciencing. 2017.

46. G Gastone Mascetti, Unihemispheric sleep and asymmetrical sleep: behavioral, neurophysiological, and functional perspectives. Nat Sci Sleep. 2016;8:221-234.

47. S Chanvallon, C Blois-Heulin, R de Latour, et al. Spontaneous approaches of divers by free-ranging orcas (Orcinus orca): age-and sex-differences in exploratory behaviours and visual laterality. Scientific Reports. 2017;8:1-7.

48. National Oceanic and Atmospheric Administration. NOAA fisheries.

49. Orca communication. OrcaLab.

50. R. Wellard, C Erbe, L Fouda, et al. Vocalisations of Killer Whales (Orcinus orca) in the Bremer Canyon, Western Australia. PLOS ONE. 2015;10(9):1-19.

51. L Dayton. Killer whales communicate in distinct. Dialects. 1990.

52. Communication \& echolocation. SeaWorld Parks \& Entertainment.

53. Clode D. Killers in Eden, The Story of a Rare Partnership Between Men and Killer Whales. $2^{\text {nd }}$ ed. Melbourne: Museum Victoria; 2011. 